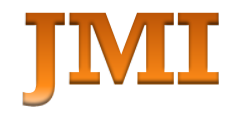

\title{
Musyarakah Mutanaqishah (diminishing partnership) pada pembiayaan perumahan.
}

\author{
Memet Agustiar ${ }^{1}$ \\ ${ }^{1}$ Ketua Prodi Ekonomi Islam, Fakultas Ekonomi dan Bisnis, Untan, INDONESIA, email: \\ memet.agustiar@ekonomi.untan.ac.id
}

\begin{abstract}
ABSTRAK
Musyarakah Mutanaqishah (MMQ) adalah salah satu bentuk baru dalam pembiayaan perumahan. MMQ berdasarkan pada akad syirkah yang disandingkan dengan akad jual beli (bai'), dan akad sewa (ijarah) Tulisan ini mengupas tentang apa itu MMQ, apa masalah utama yang muncul dalam aplikasinya. Penelitian ini mendapatkan bahwa MMQ adalah wujud yang dinamis dalam pembelian perumahan di mana kedua belah pihak diberlakukan sebagai pemodal. Kerjasama para pemitra akan berakhir dengan kemitraan yang berkurang secara bertahap (diminishing partnership) dan membuat satu pihak menjadi pemilik penuh atas asset yang dimiliki mereka. Ada berbagai masalah muncul dalam MMQ terutama dikaitkan dengan ta'alluq (multi akad) dan juga masalah dalam status kepemilikan asset. DSN-MUI terus saja memberikan kebijakan terbaik untuk menyelesaikan kompleksitas dalam pembiayaan Syariah di mana aspek legal, operasional dan syariah yang sering tidak singkron satu sama lainnya.
\end{abstract}

Kata Kunci: Musyarakah, Musyarakah Mutanaqishah, Ta’alluq, perumahan 


\section{PENDAHULUAN}

Permintaan akan rumah terus meningkat bersamaan dengan meningatnya jumlah penduduk. Di Indonesia ada sekitar 13.793 pengembang perumahan dan 19 asosiasi perumahan yang telah terdaftar di Sistem regestrasi pengembang (Sisreg)2. Hingga 1 Juli 2019 telah dibangun sebanyak 601.205-unit rumah dalam Program Satu Juta Rumah. Jumlah tersebut terdapat 456.974-unit rumah masyarakat berpengasilan rendah. Pemerintah telah memberikan tambahan kuota Kredit Perumahan Rakyat bersubsidi kepada Bank BTN sebanyak 18.500-unit pada 2021, dan akan menambah sekitar Rp 28 Trilyun untuk pembiayaan perumahan bersubsidi di Indonesia (Bisnis.com, 2020).

Tingginya permintaan terhadap rumah telah mendorong berbagai lembaga keuangan untuk ambil bagian dalam pembiayaan perumahan. Perbankan Syariah sebagai sebuah model pembiayaan telah ikut serta dalam pembiayaan perumahan tersebut, terutama untuk menyediakan fasilitas pembiayaan kepada konsumen perumahan yang bersubsidi. Ada tiga pola pembelian rumah dalam ekonomi Syariah yang biasa dilakukan yaitu (1) Murabahah (jual beli), (2) Ijarah Muntahiyah Bittamlik (IMBT), dan (3) Musyarakah Mutanaqishah (MMQ). Ketiga pendekatan ini mengandung akad yang berbeda satu sama lain. Murabahah memakai akad jual beli (bai'), IMBT memakai akad sewa (ijarah) dan MMQ memakai akad kerjasama permodalan (musyarakah). Kami tidak membahas dua akad awal, tetapi kami hanya berfokus pada pembiayaan MMQ. Istilah MMQ lebih dikenal di Indonesia, sedang di Malaysia istilahnya adalah MMP (Musyarakah Mutanaqishah Partnership).

Tulisan ini akan membahas apa itu MMQ untuk pembiayaan perumahan di Indonesia. Kami membagi tulisan ini dengan terlebih dahulu membahas apa itu musyarakah dan kemudian dilanjutkan dengan MMQ. Tulisan diulas berdasaran beberapa terbitan pendukung dari fatwa-fatwa Dewan Syariah Nasional (DSN), buku pedoman dari Otoriras Jasa Keuangan (OJK) dan beberapa tulisan ilmiah yang tersedia pada beberapa jurnal.

\section{MUSYARAKAH}

Dewan Syariah Nasional (2000) menyatakan bahwa masyarakah adalah sebuah bentuk pembiayaan yang menggunakan akad syirkah (kemitraan atau partnership atau joint venture). Syirkah atau Musyarakah berasal dari akar kata dalam bahasa arab yaitu syirkatan (mashdar/kata dasar) dan syarikah (fi'il madhi/kata kerja) yang berarti mitra/sekutu/kongsi/serikat. Fatwa Dewan Syariah Nasional nomor: 08/DSNMUI/VI/2000 tentang pembiayaan musyarakah, mengatur hubungan kerjasama (partnership) antara lembaga keuangan syariah (LKS) dan pihak lain (nasabah). Musyarakah bekerja atas dasar pekerjaan yang dihandle bersama para pemodal. Para pemodal dapat menyetorkan sahamnya dalam bentuk uang, emas, perak dan hartaharta lainnya yang dapat dinilai. Musyarakah bukan usaha perseorangan, tetapi merupakan bagian dari dua orang atau lebih.

Model di bawah ini menunjukan hubungan antara harga asset dan Lembaga yang bermitra. Kita mengasumsikan ada tiga orang yang bekerjasama dan mereka memiliki porsi modal masing-masing.

https://ekonomi.bisnis.com/read/20200110/47/1188939/pengin-beli-rumah-bersubsidi-cek-ini-agar-tak-tertipu. 


$$
P a=p m 1+p m 2+p m 3
$$

Di mana, $\mathrm{Pa}=$ harga asset, pm 1,2,3 adalah jumlah pemodal dalam kemitraan yang ditunjukan dengan kontribusi masing masing pemodal. Atas rumus itu maka setiap pemodal memilik share sebesar yang mereka sanggupi. Besarnya share dapat dikomversikan ke dalam porsi-porsi masing-masing pemodal, sebagai berikut:

$$
r=\frac{p m 1}{P m}+\frac{p m 2}{P m}+\frac{p m 3}{P m}=100 \%
$$

Di mana, $\mathrm{r}$ adalah porsi modal, pm 1,2,3 adalah para pihak yang berpartisipasi dalam permodalan, dan Pm total saham.

Share (porsi modal) bermanfaat untuk menentukan status masing-masing dalam kerjasama sehingga menjadi indikator dalam pembagian dividen pada setiap waktu usaha (misalnya satu tahun). Siapa yang punya porsi besar maka dia akan mendapatkan bagian keuntungan yang lebih banyak dari yang lain. Syirkah yang porsi modalnya tidak sama disebut dengan syirkah inan, sedangkan jika porsi modalnya sama maka disebut dengan syirkah mufawadhah. Besar kecilnya share ditentukan pada saat awal mendirikan usaha, dan dapat terus berkembang naik akan turun setelah melalui proses dalam Rapat Umum Pemegang Saham (RUPS). Dalam Tabel 1 kita melihat ada beberapa jenis akad syirkah. Pembagaian ini didasari atas pengalaman yang pernah tertulis dalam riwayat-riwayat terdahulu.

Tabel 1. Jenis-jenis syirkah

\begin{tabular}{l|ll|l|l}
\hline \multicolumn{2}{l}{ Syirkah Amlaq (bukan karena akad) } & \multicolumn{3}{c}{$\begin{array}{l}\text { Syirkah Uqud (bersepakat untuk berakad untuk } \\
\text { tujuan berusaha/bisnis) }\end{array}$} \\
\hline $\begin{array}{l}\text { Amlak ikhtiari } \\
\text { (optional) }\end{array}$ & $\begin{array}{l}\text { Amlak ijbari } \\
\text { (otomatis/mutlak) }\end{array}$ & $\begin{array}{l}\text { Syirkah amwal } \\
\text { (harta/aset) }\end{array}$ & $\begin{array}{l}\text { Syirkah } \\
\text { abdan } \\
\text { (ketrampilan) }\end{array}$ & $\begin{array}{l}\text { Syirkah wujuh } \\
\text { (reputasi/good } \\
\text { will) }\end{array}$ \\
\hline $\begin{array}{l}\text { Berbentuk } \\
\text { Ikhtiari (hibah, } \\
\text { wasiat) }\end{array}$ & $\begin{array}{l}\text { Misalnya karena } \\
\text { orang tua } \\
\text { meninggal (soal } \\
\text { waris) }\end{array}$ & $\begin{array}{l}\text { Amwal inan } \\
\text { (jumlah modal } \\
\text { beda) }\end{array}$ & $\begin{array}{l}\text { Kualitas } \\
\text { ketrampilan } \\
\text { (skill) para } \\
\text { pemodal }\end{array}$ & $\begin{array}{l}\text { Memilki } \\
\text { reputasi baik } \\
\text { (kredibilitas) }\end{array}$ \\
& $\begin{array}{l}\text { Amwal } \\
\text { mufawadhah } \\
\text { (jumlah modal } \\
\text { sama) }\end{array}$ & \\
\hline Tidak memerlukan akad wakalah & $\begin{array}{l}\text { Ada akad wakalah, bahwa para pihak pemodal bisa } \\
\text { mendelegasikan kepada pihak lain yang memilki } \\
\text { ketrampilan dan reputasi baik untuk menjalankan } \\
\text { usaha }\end{array}$ \\
\hline
\end{tabular}

Sumber: OJK, 2016

Akad syirkah itu terdiri dari dua jenis. Pertama adalah syirkah tanpa akad dan syirkah untuk tujuan bisnis. Tanpa akad maksudnya bahwa suatu kejadian transkasi bersifat terpaksa, bukan karena diatur diawal, misalnya membagi waris karena orang tua meninggal. Mereka tidak sedang merencanakan sebuah akad, namun karena faktor yang memaksa sehingga mereka melakukannya. Kedua adalah akad syirkah yang bertujuan bisnis (berusaha). Ada tiga kemitraan di sini yaitu kemitraan dalam permodalan (uang dan asset lainnya), kemitraan karena keahlian, dan kemitraan karena adanya reputasi baik (goodwill). Tidaklah hanya cukup dengan kemitraan dalam bentuk uang (walaupun itu penting), namun harus pula didorong kearah kerjasama berdasarkan keahlian dan reputasi (OJK, 2000). Apalagi dalam akad syirkah ada kemungkinan menggunakan akad wakalah (medelegasian pengurusan usaha kepada pihak lain) yang tentu didasari atas keahlian dan reputasi yang baik. 
Para pemodal yang bermirta biasanya tidak melakukan sendiri usaha mereka, melainkan menujuk (wakalah) kepada para ahli yang pandai melakukan organisasi bisnis (seperti bertindak sebagai direktur). Para pemodal sendiri berada sebagai pemegang saham dan sebagian ada yang ditunjuk sebagai komisaris.

\section{MUSYARAKAH MUTANAQISHAH (MMQ)}

Munculnya MMQ tidak terlepas dari munculnya pembelian rumah secara bersubsidi yang ditawarkan pemerintah. Pemerintah dapat memberi talangan berupa uang bantuan kepada khalayak dalam membeli rumah. Dengan demikian pembeli rumah diuntungan dari uang subsidi yang bisa dijadikan sebagai modal mereka dalam bekerjasama dengan pihak bank. Dalam sistem murabahah, pembeli boleh tidak memiliki uang muka demikian juga pada sistem IMBT, sehingga pembiayaan adalah full oleh bank dan kemudian dicicil dan disewa sesuai dengan jumlah yang disetujui. Tetapi pada MMQ, pihak pembeli harus dalam status memiliki dana sendiri (sebagai uang muka) yang dijadikan saham mereka. Kerjasama MMQ memerlukan dua porsi atau lebih dari modal para pihak yang saling berkerjasama (Osmani dan Abdullah, 2010).

Pada bagian pertama kita sudah menjelaskan soal musyarakah (syirkah) dengan beberapa aspek. Kemudian kita ingin mengatahui Mutanaqishah atau kemitraan yang menurun secara bertahap atau diminishing partnership (Basyariah, 2018). Apa yang dimaksud dengan kata 'menurun tersebut dan secara bertahap', maka mari kita ikut penjelasan berikut ini.

Kita pertama kali harus menjelaskan bahwa kerjasama syirkah adalah kerjasama satu atau dua orang dan bisa lebih. Kerjasama tersebut diukur dari status mereka dalam besar kecilnya modal yang mereka tanamkan. Untuk kasus di sini, kita membicarakannya dalam kontek pembiayaan perumahan. Ada beberapa akad yang dipergunakan dalam kerjasama pembiayaan perumahan.

1. Akad syirkah, yaitu kerjasama yang dilakukan oleh lembaga keuangan (bisa bank atau lainnya) dan nasabah (kita asumsikan hanya ada dua kemitraan saja).

2. Akad jual beli (bai'). Setelah mereka bersepakat bekerja sama maka selanjutnya adalah mereka secara bersama akan membeli rumah. Bank membayar sejumlah uang (biasanya lebih besar) dan nasabah menyediakan modal yang bisa diperoleh melalui subsidi pemerintah. Siapa yang membeli ? Aspek legalnya mengatakan harus keduanya karena alasan berakad syirkah. Kemudian setelah dibeli, kepada siapa kepemilikan itu diperuntukan. Jawabnya adalah untuk keduanya yang didasari oleh jumlah besaran saham.

Akad ijarah (sewa). Setelah barang dibeli, maka nasabah bermaksud untuk menyewa rumah tersebut. Sebagai sewa, maka ada tiga hal yang penting (1) membayar sewa dalam jumlah tertentu, dan (2) membayar harga rumah, dan (30 membayar biaya lainnya, jika ada. Anggaplah kemudian sewa sudah dibayarkan bersamaan dengan cicilan rumah dalam waktu yang bertahap. Pembiayaan sewa dan cicilan rumah ini nantinya akan dikonversikan ke saham lembaga keuangan sehingga mengurangi saham secara bertahap. Di sini ada konversi otomatis yang mengurangi saham lembaga keuangan. Akibatnya saham bank akan menurun, dan saham nasabah akan menaik. Hingga titik terakhir, maka saham bank akan menjadi nol dan saham nasabah akan menjadi 100\%. Inilah yang disebut sebagai kerjasama yang berkurang secara bertahap (dari sisi bank), namun meningkat secara bertahap (dari sisi 
nasabah). Dalam posisi 100\% maka akte kepemilikan berubah menjadi milik nasabah (Meera, 2018; Meera dan Razak, 20

Tabel 2. Simulasi pembelian rumah seharga Rp 300 juta dalam masa 8 tahun

\begin{tabular}{|c|c|c|c|c|c|c|c|c|}
\hline $\begin{array}{l}\text { Tahun } \\
\text { Cicilan }\end{array}$ & $\begin{array}{l}\text { Cicilan } \\
\text { harga } \\
\text { rumah } \\
\text { (Rp) }\end{array}$ & $\begin{array}{l}\text { Sewa } \\
\text { (Rp) }\end{array}$ & $\begin{array}{l}\text { Jumlah } \\
\text { bayaran } \\
\text { (Rp) }\end{array}$ & $\begin{array}{l}\text { Cicilan } \\
\text { nasabah } \\
(\mathrm{Rp})\end{array}$ & $\begin{array}{l}\text { Nominal } \\
20 \% \\
\text { saham } \\
\text { nasabah } \\
\text { (Rp) }\end{array}$ & $\begin{array}{l}\text { Nominal } \\
80 \% \\
\text { saham } \\
\text { bank (Rp) }\end{array}$ & $\begin{array}{c}\text { Saham } \\
\text { nasabah } \\
(\%)\end{array}$ & $\begin{array}{c}\text { Saham } \\
\text { bank } \\
(\%)\end{array}$ \\
\hline & A & B & $\mathrm{C}$ & $\mathrm{D}$ & $\mathrm{E}$ & F & G & $\mathrm{H}$ \\
\hline $\mathbf{0}$ & & & & & 60000 & 240000 & $20 \%$ & $80 \%$ \\
\hline 1 & 37500 & 5000 & 42500 & 30000 & 90000 & 210000 & $30 \%$ & $70 \%$ \\
\hline 2 & 37500 & 5000 & 42500 & 30000 & 120000 & 180000 & $40 \%$ & $60 \%$ \\
\hline 3 & 37500 & 5000 & 42500 & 30000 & 150000 & 150000 & $50 \%$ & $50 \%$ \\
\hline 4 & 37500 & 5000 & 42500 & 30000 & 180000 & 120000 & $60 \%$ & $40 \%$ \\
\hline 5 & 37500 & 5000 & 42500 & 30000 & 210000 & 90000 & $70 \%$ & $30 \%$ \\
\hline 6 & 37500 & 5000 & 42500 & 30000 & 240000 & 60000 & $80 \%$ & $20 \%$ \\
\hline 7 & 37500 & 5000 & 42500 & 30000 & 270000 & 30000 & $90 \%$ & $10 \%$ \\
\hline 8 & 37500 & 5000 & 42500 & 30000 & 300000 & 0 & $100 \%$ & $0 \%$ \\
\hline & 300000 & 40000 & 340000 & 240000 & & & & \\
\hline
\end{tabular}

Catatan:

A adalah $\mathrm{Rp} 300$ juta dibagi 8 tahun, B sewa yang direncanakan, C total sewa dan cicilan rumah, D total cicilan nasabah (diluar sewa), diperoleh dari Rp 240 juta dibagi 8 tahun. Setiap tambahan dari Rp 60 juta ditambah dengan $R p 30$ juta= Rp 90 Juta, dan seterusnya. Untuk pihak bank, setiap setoran mengurangi saham (Rp240 juta - Rp 30 juta) = Rp 210 juta. G dan Hadalah share saham di mana kolom E dibagi dengan Rp300 juta, dan untuk bank kolom F dibagi dengan Rp300 juta.

Pada Tabel 2 memperlihatkan bagaimana simulasi pembelian rumah seharga Rp300 juta dalam masa 8 tahun. Nasabah memiliki saham sebesar 20\% dan Bank sebesar 80\%. Bila kedua bermitra maka nasabah menyetorkan dana sebesar Rp 60 juta (20\% dari Rp 300 juta) dan bank sebesar Rp 240 juta. Pada Tabel 2, khususnya kolom D, nasabah hanya membayar setoran sekitar Rp 30 juta setiap tahun (bayaran cicilan rumah sengaja tidak dimasukan dalam simulasi ini). Nasabah tidak membayar seluruh cicilan rumah, tetapi hanya besar saham yang ia tidak miliki (80\% atau Rp 240 juta). Dengan kata lain, nasabah hanya membayar Rp30 juta tiap bulan, bukan Rp 37,5 juta.

Dari uraian yang tertera pada table 2 maka dapat kita simpulkan bahwa:

1. Setiap setoran nasabah akan divestasi ke saham bank, sehingga saham bank terus menurun secara bertahap. Kita lihat bagaimana saham bank menurun dari $80 \%$ ke $70 \%$ ke 60\% hingga pada tahun ke delapan menjadi $0 \%$.

2. Sebaliknya saham nasabah terus meningkat dari $20 \%$ menjadi $30 \%$ dan akhirnya menjadi $100 \%$.

3. Pada posisi akhir, rumah tersebut $100 \%$ dimiliki oleh nasabah dan bank tidak lagi memiliki rumah tersebut.

4. Pada kasus akhir maka kerjasama itu akan berakhir dan transaksi MMQ sudah selesai dilakukan. 


\section{PERSOALAN DI BALIK MMQ}

Transaksi pembiayaan MMQ mengandung sejumlah masalah baik dilihat dari aspek syariat, legal dan operasional. OJK telah membuat ringkasan mengenai masalah-masalah yang muncul tersebut. Penulis akan membuat ringkasan mengenai masalah-masalah itu dilihat dari ke tiga aspek tersebut.

1. Prinsip 'dua akad bersatu dalam satu barang (two-in-one). Secara syariat akad muamalah tidak boleh terjadi dua akad dalam satu transaksi. Misalnya, jika kita membeli sepeda motor, maka tidak boleh memberlakukan dua akad, yaitu jika dibeli dengan tunai harganya sebesar Rp 15 juta, dan dibeli dengan kredit harganya menjadi Rp 18 juta. Ini merujuk ke satu pembelian barang (yaitu motor) yang dikenakan dua akad sekaligus. Contoh lain adalah misalnya "jualah barang ini seharga satu dinar atas seharga seekor kambing dengan rincian yang komplit (ini mempersyaratkan dengan benda lain). Jualah rumah kamu seharga sekian asal kamu menjual kebunmu seharga sekian. Jualah gandum (satu keranjang) ini seharga dua bulan lagi senilai dua keranjang.

Two in one tidak dibenarkan karena bersifat mengikat terhadap sebuah jual beli, baik dibeli tunai atau kredit, dan perubahan harga karena faktor waktu yang belum jelas kedepannya seperti apa. Untuk pembelian perumahan seakan ada seperti twoin-one, seperti ada akad syariah dan ada akad jual beli dan ta'alluq.

2. Ta'alluq (hybrid contract), yaitu akad yang saling melengkapi satu sama lain. Kita melihat dalam akad MMQ ada tiga akad yang berlangsung Bersama, syirkah, bai' dan ijarah. Namun karena sifatnya saling melengkapi, bukan eksekusi seperti kasus two-in-one, maka hal ini dibenarkan oleh Dewan Syariah Nasional (DSN). Ketiganya saling melengkapi satu sama lainnya. DSN-MUI terus berupaya mencari dalil-dalil (rekayasa positif) yang memungkinkan bisanya terpenuhi akad muamalah di kalangan umat (Agustiar, 2021).

3. Agunan dalam pembiayaan MMQ menjadi pertanyaan adalah siapa pemilik barang tersebut. Kedua mitra yang saling bekerja sama (syirkah) maka pembelian barang harus memakai nama siapa. Karena dibeli dengan pola saham maka sebaiknya kepemilikan asset atas nama berdua, bukan bank saja. Inilah bukti bahwa asset tersebut atas nama syirkah. Jika telah dibeli maka nasabah akan menyewa dan membayar seharga cicilan yang disepakati. Jika sampai suatu waktu diakhir penyewaan, saham keduanya akan berubah, nasabah menaik dan bank menurun.

4. Nasabah (yang sebenarnya adalah pemilik perusahaan) harus menanggung sejumlah biaya seperti administrasi dan biaya asuransi. Bahkan mungkin biaya pemeliharan selama proses penyewaan berlangsug, karena rumah bersifat depresiatif (mudah berkurang fisikalnya). Dalam prakteknya hal-hal seperti ini menjadi tanggungan nasabah.

\section{KESIMPULAN}

Fatwa tetang musyarakah mutanaqishah lahir di Indonesia tahun 2008 yang dibuat melalui fatwa DSN-MUI Jakarta. Peper ini telah mereview beberapa pengertaian dasar, cara menghitung dan masalah dibalik MMQ. Penulis mendapatkan bahwa MMQ adalah bentuk yang lebih dinamis dalam kredit perumahan di mana para pihak diberlakukan sebagai pemodal (saham). Dengan cara ini, maka kepemilikan disusun 
berdasarkan kerjasama yang menurun secara bertahab bagi bank dan meningkat secara bertahap bagi nasabah.

MMQ juga memiliki ruang dan celah syariah yang menimbulkan pertanyaan. Potensi adanya akad ta'alluq dan two-in-one menjadi banyak kritik untuk itu. Namun DSN-MUI masih membenarkan cara ini dengan sejumlah teleah akademis yang mereka lakukan. Hampir disemua akad mengandung masalah operasional dan legal. Hukum nasional kita memang belum terlalu akomodatif dengan kemauan Syariah. Dengan kasus-kasus seperti itu, maka fatwa DSN-MUI akan memberikan kebijakan terbaik dalam menyelesaian semua kompleksitas yang ada.

\section{REFERENSI}

Agustiar, Memet. 2021. Perkembangan Kritik Terhadap Bank Islam: Jurnal Muamalat Indonesia, April 2021, Vol 1 (1): 31-60

Basyariah, N. 2018. Analisis Implementasi Pembiayaan Musyarakah Mutanaqishah Pada Perbankan Syariah di Indonesia. Jurnal Muqtasid, 9(2), 2018.

Dewan Syariah Nasional, 2000. Fatwa DSN No:08/DSN-MUI/VI/2000 tentang Pembiayaan Musyarakah, DSN-MUI Jakarta

Dewan Syariah Nasional. 2008. Fatwa DSN-MUI No: 73/DSN-MUI/XI/2008 tentang Musyarakah Mutanaqisah, DSN-MUI Jakarta.

Meera, A. K. M. 2018. Islamic Home Financing Through Musharakah Mutanaqisah: A Crowdfunding Model. Concept and Application of Shariah For the Construction Industry: Shariah Compliance in Construction Contracts, Project Finance And Risk Management, 181.

Meera, A. K. M., \& Razak, D. A. 2005. Islamic Home Financing through Musharakah Mutanaqisah and al-Bay Bithaman Ajil Contracts: A Comparative Analysis. Review of Islamic Economics, 9(2), 5.

Osmani, N. M., \& Abdullah, M. F. 2010. Musharakah mutanaqisah home financing: A review of literatures and practices of Islamic banks in Malaysia. International Review of Business Research Papers, 6(2), 272-282.

Otoritas Jasa Keuangan, 2016. Standard produk perbankan syariah: Musyarakah dan Musyarakah Muntanaqishah, OJK Jakarta

Bisnis Com. 2020. Pengin beli rumah bersusbsidi cek agar tidak tertipu. Retrieved from https://ekonomi.bisnis.com/read/20200110/47/1188939/pengin-belirumah-bersubsidi-cek-ini-agar-tak-tertipu 